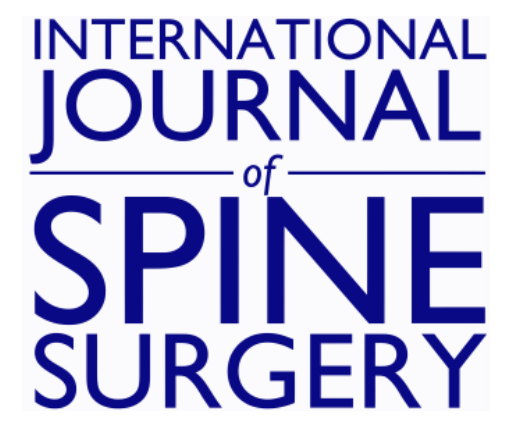

\title{
Posterior lumbar interbody fusion with instrumented posterolateral fusion in adult spondylolisthesis: description and association of clinico-surgical variables with prognosis in a series of 36 cases
}

Monica Lara-Almunia, Juan A. Gomez-Moreta and Javier Hernandez-Vicente

Int J Spine Surg 2015, 9 ()

doi: https://doi.org/10.14444/2022

http://ijssurgery.com/content/9/22

This information is current as of April 26, 2023.

Email Alerts Receive free email-alerts when new articles cite this article. Sign up at:

http://ijssurgery.com/alerts

The International Journal of Sdpine Subrgerthttp://ijssurgery.com/ by guest on April 26, 2 2397 Waterbury Circle, Suite 1, 


\section{Posterior lumbar interbody fusion with instrumented posterolateral fusion in adult spondylolisthesis: description and association of clinico-surgical variables with prognosis in a series of 36 cases}

Monica Lara-Almunia, MD, ${ }^{1}$ Juan A. Gomez-Moreta, MD, ${ }^{2}$ Javier Hernandez-Vicente, $M D^{2}$

${ }^{1}$ Department of Neurosurgery, Son Espases University Hospital, Mallorca, Spain 2Department of Neurosurgery, University Hospital of Salamanca, Salamanca, Spain

\section{Abstract}

\section{Background}

We present our experience in the treatment of patients with isthmic or degenerative spondylolisthesis, by means of a posterior lumbar interbody fusion (PLIF) and instrumented posterolateral fusion (IPLF), and we compare them with those published in the literature. We analyse whether there exists any statistical association between the clinical characteristics of the patient, radiological characteristics of the disease and our surgical technique, with the complications and the clinical-radiological prognosis of the cases.

\section{Method}

We designed a prospective study. A total of 36 cases were operated. The patients included were 14 men and 22 women, with an average age of $57.17 \pm 27.32$ years. Our technique consists of PLIF+IPLF, using local bone for the fusion. The clinical results were evaluated with the Visual Analogical Scale (VAS) and the Kirkaldy-Willis criteria. The radiological evaluation followed the Bratingan (PLIF) and Lenke (IPLF) methodology. A total of 42 variables were statistically analysed by means of SPSS18. We used the Paired Student's T-test, logistic regression and Pearson's Chi-square-test.

Results

The spondylolisthesis was isthmic in 15 cases and degenerative in 21 cases. The postoperative evaluations had excellent or good results in $94.5 \%(n=34)$, with a statistically significant improvement in the back pain and sciatica $(\mathrm{p}<0.01)$. The rate of circumferential fusion reached was approximately $92 \%$.We had $13.88 \%$ of transitory morbility and $0 \%$ of mortality associated with our technique. A greater age, degree of listhesis or length of illness before the intervention, weakly correlated with worse clinical results $(\mathrm{p}<-0.2)$. In our series, the logistical regression showed that the clinical characteristics of the patient, radiological characteristics of the lesion and our surgical technique were not associated with greater postoperative complications.

\section{Conclusion}

Although a higher level of training is necessary, we believe that the described technique is a very effective decision in cases of spondylolisthesis, isthmic or degenerative, refractory to conservative treatment, for the obtaining the best clinical results and rates of fusion, with similar risks to those of the other published techniques. Our statistical analysis could contribute to improve outcomes after surgery.

KEYWORDS: SPONDYLOLISTHESIS, INSTRUMENTED POSTEROLATERAL FUSION, POSTERIOR LUMBAR INTERBODY FUSION, SPINAL FUSION, CAGES VOLUME 9 ARTICLE 22 DOI: 10.14444/2022

\section{Introduction}

Spondylolisthesis is a pathological condition that is defined as the olisthy of one vertebral body over another. The term was coined for the first time in 1854

\section{by Killian. ${ }^{1}$}

There are different types of spondylolisthesis. Wiltse et al. performed the first systematic classification according to etiology, differentiating between congeni- 
tal, isthmic, degenerative, pathological and iatrogenic. $^{2}$

In adults, the most frequent are those due to lesions of the interarticular isthmus and of degenerative origin. The incidence of isthmic spondylolisthesis is between $6 \%$ and $7 \%,{ }^{3}$ and of degenerative spondylolisthesis is around 8.7\% ${ }^{4}$ Both types are more commonly found in women.

The clinical presentation and natural history of spondylolisthesis is variable. Chronic pain of long evolution is normally the earliest and most important manifestation. It is sometimes found by accident, while in other cases, the process can evolve until it severely compromises the spinal content at the affected level. ${ }^{5,6}$

Despite many publications related to the distinct methods of fixation and fusion that can be used in the treatment of different types of spondylolithesis, the handling of this condition is still very controversial.

Since the first description of the posterior lumbar interbody fusion for the treatment of the different types of degenerative lumbar pathology, among them spondylolisthesis, in 1985 by Cloward, ${ }^{7}$ to now, the procedure has gone through different degrees of acceptance, as well as many adaptations, variations and innovations, but still there is no universally accepted technique.

We present the results of our experience in the treatment of adults with isthmic or degenerative spondylolisthesis by means of posterior circumferential fusion, achieved with the combination of posterior lumbar interbody fusion (PLIF) and instrumented posterolateral fusion (IPLF), and we compare them with those published in the literature.

Our group has developed a detailed descriptive and analytical study. We study whether the clinical characteristics of the patient, the radiological characteristics of the condition and our surgical technique are associated with the clinical-radiological result shown in the short and long term by our patients. This is unusual in the literature.

\section{Materials and Methods}

\section{Patients and Data Collection}

Our team has carried out a prospective study of a sample of 36 patients with vertebral spondylolisthesis submitted to PLIF + IPLF surgery between 2001 and 2010 , as at the beginning of this decade the technique first began to be used in our institution.

A total of 42 variables referring to the demographic and clinical characteristics of the patient, radiological characteristics of the vertebral process and peculiarities of the surgical technique were analysed in each of the cases for the configuration of the data base. The information was obtained by means of a detailed revision of the clinical histories and the imaging tests.

In our work we use, as a nomenclature, the WiltseNewman classification $(1976)^{2}$ of the types of spondylolisthesis (Type I: congenital, Type II: isthmic, Type III: degenerative Type IV: Traumatic, Type V: Pathological and Type VI: iatrogenic), and the classification of the grade of forward displacement of the superior vertebral body on the inferior from Meyerding (1932). ${ }^{8}$

\section{Surgical planning \\ Inclusion and exclusion criteria}

We considered candidates for surgical treatment those patients with Type II spondylolisthesis, ${ }^{2}$ isthmic, or Type III spondylolisthesis, ${ }^{2}$ degenerative, at any grade (grades I-V, Meyerding classification ${ }^{8}$ ), which were associated with spinal symptoms along with neurological symptoms of at least one year of evolution, and recalcitrant to conservative, pharmacological or rehabilitative treatment.

Exclusion criteria were the pediatric population (Type I spondylolisthesis), the presence of severe spinal injury (Type IV spondylolisthesis), tumor or infection (Type V spondylolisthesis), and those patients where there were either obvious psychological alterations or the cases were related with legal problems, such as work or traffic accidents. Type VI spondylolisthesis is not object of this work. The presence of previous surgery in relation to the lumbar discs at the levels to be intervened was not consid- 
ered as exclusion criteria.

\section{Surgical technique}

All the surgical techniques were performed by the same surgeon, senior author ( JHV), using the same method.

The patient is placed in prone position on the Wilson frame, checking that the abdomen remains as free as possible from external pressure in order to obtain minimum epidural bleeding during the procedure. After a sufficiently extensive cutaneous incision, the muscular masses are broadly dissected and separated, the vertebral pedicles are identified and the pedicle screws are placed. Next a wide bilateral decompressive laminectomy is performed, with resection of the joints, if necessary, and the fibrous intraspinal tissue, characteristic of the lysis areas, if that is the case. Immediately after, to carry out the PLIF, the affected disc or discs are removed and disc spaces are cleared with shavers, placing in them two intersomatic arthrodesis cages of appropriate size, ones on each side of the midline. These cages are filled with autogenous bone coming from the posterior bony structures previously removed and carefully prepared for that aim (spinous processes, laminas and joints). Then, we proceed to position the bars on both sides, which are fixed to previously placed screws, and to the interpositioning of the bony graft, also of local origin, between the superior and inferior transverse processes of the operated levels, whose dorsal surface had been previously drilled to boost the fusion, and finishing in this way the IPLF.

The different surgical times, as well as the correct final position of the system, were always inspected by means of fluoroscopy. Intraoperative neurophysiological monitoring never was employed.

In all the cases, radiographs and CT scan were carried out at 48-72 hours from the surgery (Figure 1). If the study was considered to be normal (screws and cages in the correct position), the sitting position and posterior mobilization of the patient, with extension corset in the first 3 months, were indicated (Figure 2).

\section{Clinical and radiological evaluation}

The clinical controls, evaluating back pain, radicular pain and total functional result, and radiological characteristics, evaluating the bony fusion and probable complications derived from the procedure, were repeated at 3, 6 and 12 months after surgery (radiographs and CT scans).

The clinical evaluation of preoperative and postoperative back pain and sciatica was carried out by means of the visual analogical scale (VAS) of pain, a subjective unidimensional scale that extends from $0-10$, with" 0 " as the absence of pain and " 10 " as the existence of the maximum pain. ${ }^{9}$ The total clinical result

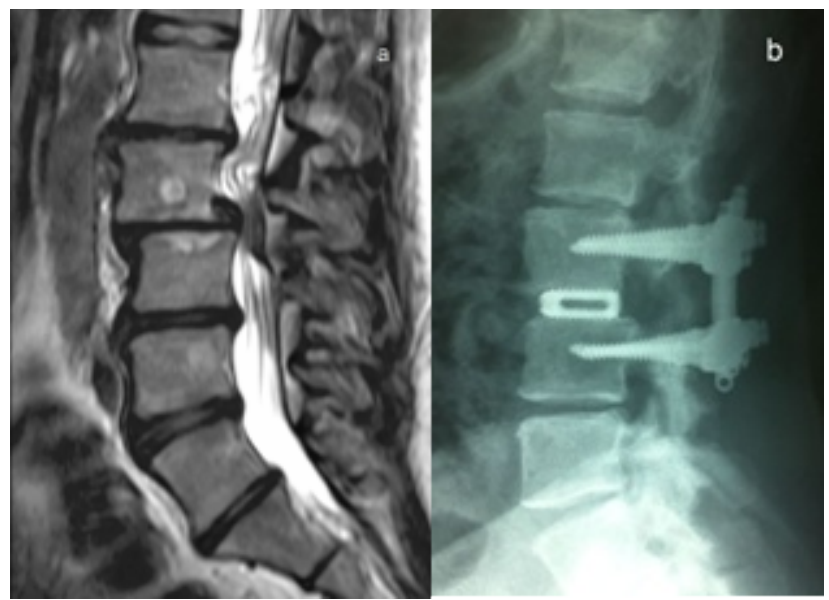

Fig. 1. Case 15. A 41 year old man with Grade II degenerative spondylolisthesis, Level L3-L4. (a), the preoperative sagittal T2-weighted $M R I$ illustrates the spondylolisthesis and the retropulsion of the intervertebral disc. (b), the 48-72 h postoperative sagittal radiograph shows PLIF + IPLF, with restoration of the disc space height and improvement of the spondylolisthesis.

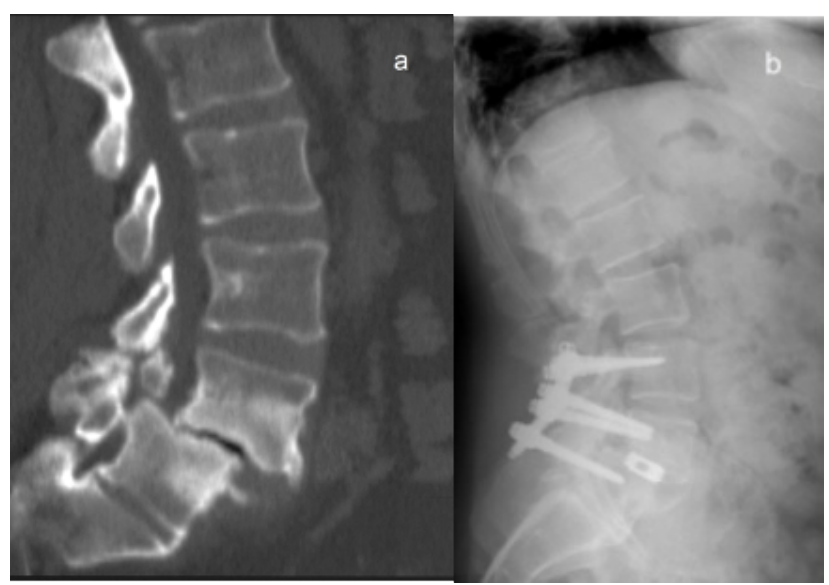

Fig. 2. Case 36. A 46 years old man with Grade II isthmic spondylolisthesis, Level L4-L5. (a), the preoperative sagittal CT shows the pathology. (b), the 48-72 $\mathrm{h}$ postoperative sagittal radiograph illustrates the construction in an adequate position. PLF + IPLF with six screws were employed. 
was estimated with the Kirkaldy-Wyllis criteria. ${ }^{10}$

The radiological evaluation of the fusion degree of both the intersomatic (PLIF) and posterolateral (IPFL) was performed by the main surgeon and the rest of the authors of this work with the same criteria. The evaluation of the radiographs at the aforementioned times was made independently by each author. Later meetings were held (approximately at 3, 6 and 12 months) where each author gave their results, the cases were debated and in case of any discrepancy, the opinion of a radiologist was requested (not included as coauthor of the work). As a last resort and, in case of doubt, the result of "probable radiological fusion" was prioritized against that of "complete radiological fusion". The criteria used will be detailed in the following paragraphs.

The intersomatic fusion (PLIF) was established according to the criteria described by Brantigan et al. ${ }^{11}$ A meticulous description of the criteria (tables and figures) is presented in the original article. Those authors employed a scale of 5 levels, defining each one of them in the summarized manner as follows: Level 5 , radiological fusion; Level 4, probable radiological fusion; Level 3, uncertain radiological stage; Level 2, probable radiographic pseudarthrosis; Level 1, obvious radiographic pseudarthrosis. Levels 5 and 4 usually have excellent radiological outcome: these cases normally do not return to the operating room for intersomatic pseudoarthrosis or cages failure.

The degree of posterolateral fusion (IPFL) was determined employing the method used by Lenke et al. ${ }^{12}$ A detailed description of the criteria (tables and figures) is presented in the original work. It is specified in the following manner: Grade A, definitive fusion with bilateral thick bony masses; Grade B, probable fusion with thick bony mass in one side and thin bony mass on the other; Grade $\mathrm{C}$, no probable fusion with thin bony mass on one side and probable pseudarthrosis on the contralateral side; Grade D, no fusion, with thin bony mass on both sides with obvious bony pseudarthrosis or reabsorption of graft bilaterally. Grades A and B usually have excellent radiological outcome: these cases normally do not return to the operating room for posterolateral pseudoarthrosis, instrumentation failure, pedicle screw loosening or windshield wiper-type sign.

\section{Statistical analysis}

The statistical analysis was developed with SPSS 18 for Windows (SPSS Inc, Chicago, Illinois, USA), by means of parametric test.

The tests employed for the study of the statistical association between two independent variables were the $\chi^{2}$ test, with correction by means of the Fisher's exact test when necessary, for the qualitative variables, and the Pearson's correlation coefficient for the quantitative variables. For the studies of association between two or more independent variables, the Binary logistic regression test was applied (multivariate analysis). The analysis of statistical difference in dependent variables was carried out with the tStudent's test for paired data.

The results were considered statistically significant if $\mathrm{p}<0.05$.

\section{Results}

\section{Descriptive study}

Demographic characteristics of the patients and pathology We analysed a total of 36 patients submitted to PLIF + IPLF in our department.

The average age of the series is 57.1 years. The majority of the patients were in the 5th and 6th decades of life $(27.8 \% ; n=10)$, with an average of 56.5 years. The age range was situated between 30 and 82 years.

Our series is composed of $22(61.1 \%)$ women and 14 (38.9\%) men with a ratio of 1.57:1.

The most relevant clinical symptomatology referred to by the patients on admission for intervention was neurogenic claudication with lumbosciatic in $44.4 \%$ $(\mathrm{n}=16)$, lumbosciatic pain in $38.8 \%(\mathrm{n}=14)$ and isolated sciatica in $16.6 \%(n=6)$ of the cases. On neurological examination we found that the most highlighted was isolated motor deficit $(44.4 \% ; \mathrm{n}=16)$, followed by the absence of findings $(22.2 \% ; n=8)$ and motor sensitive changes $(19.4 \% ; n=7)$; the presence of isolated sensitive alterations was the least prevalent sign $(13.8 \% ; n=5)$.The average length of the symptomatol- 
ogy before indication for surgical treatment was $6.2 \pm 4.6$ years.

In terms of the disease presented by our patients, on 15 occasions (41.6\%) the listhesis was associated to spondylolisis, Type II spondylolisthesis, while in the remaining 21 cases $(58.3 \%)$ the spodylolisthesis had a degenerative origin, Type III spondylolisthesis.

Only two of the cases were operated on two contiguous spinal levels, both with Type III spondylolisthesis (5.5\%). In the rest of the patients, the surgery was limited to only one level (94.4\%).

The grade of listhesis, according to the Meyerding classification, showed in the total of the 38 levels intervened by our team was: Grade I in 22 (57.8\%), Grade II in 14 (36.8\%) and Grade III in $2(5.2 \%)$.

In relation to the most frequently affected level, we found that the L4-L5 level was the most prevalent with 19 (50\%) cases, followed by L5-S1 level with 16 (42.1\%) and L3-L4 with 3 (7.8\%).

$13.8 \%$ of our patients $(\mathrm{n}=5)$, had been submitted to surgical intervention of lumbar discectomy (microdiscectomy) of a level before the fixation-fusion surgery described in this work.

The demographic characteristics of the patients and pathology are shown in Table 1.

\section{Clinical results}

All the cases that presented back pain before surgery $(83.3 \% ; n=30)$ significantly reduced it a year after the intervention $(\mathrm{t}=62.7 ; \mathrm{p}<0.01)$ with the improvement being close to $80 \%$. Similarly, all the patients of our series $(100 \% ; n=36)$ referred to a decrease in the radicular pain radiating to lower limbs of at least $86.5 \%$, which was also statistically significant $(\mathrm{t}=$ $36.0 ; \mathrm{p}<0.01$; Table 2).

With respect to patient return to work, following the Kirkaldy-Willis criteria ${ }^{10}$ and taking the results of "Excellent" and "Good" as satisfactory, the rate of success in the present work was $94.5 \%(\mathrm{n}=34$; Table 3).
A year after the surgical intervention, all the cases were discharged at the last clinical control in the outpatient clinic. The total follow up rate was $100 \%$.

\section{Radiological results}

None of the patients had to return to the operating theatre due to intersomatic or posterolateral pseudarthrosis at any of the 38 levels intervened in total, a year after the intervention.

In relation with the intersomatic fusion, and according to the criteria of Brantingan et al., ${ }^{11}$ it was distributed in the following manner: 5 (radiological fusion) $=36$ levels; 4 (probable radiological fusion) $=2$ levels; 3 (uncertain radiological state) $=0$ levels; 2 (probable radiographic pseudarthrosis) $=0$ levels; and 1 (obvious radiographic pseudarthrosis) $=0$ levels.

In terms of the evaluation of the posterolateral arthrodesis, and according to the degrees of fusion of Lenke et al. ${ }^{12}$ we obtained: Grade A (definitely solid bilaterally) = 34 levels; Grade B (unilaterally solid) = 4 levels; Grade $C$ (probably not solid) = 0 levels; and Grade D (definitely not solid) $=0$ levels.

In this way, $100 \%$ of our patients presented an excellent radiological result 12 months after the intervention: Bratingan's Levels 5 or 4 for intersomatic fusion and Lenke 's Grades A or B for posterolateral fusion. A complete radiological fusion was produced in 34 out of 38 levels belonging to 33 out of 36 patients $(\approx$ $92 \%)$. The results of the intersomatic and posterolateral fusion after 1 year of follow up depending on the type of spondylolisthesis are shown in Table 4. The total follow up rate was $100 \%$.

\section{Complications}

Two patients presented a transitory neurological deficit after surgery, representing an incidence of this complication of $5.5 \%(n=2)$. In the first, we found a motor defect for severe paresia of external popliteal sciatic nerve, which improved during hospitalization, and was practically normal after rehabilitation treatment on discharge. In the second of the cases, the patient presented intense unilateral cruralgia associated to paresia of quadriceps. The CT control allowed us to demonstrate the defective situation of 
one of the fixation screws. After proceeding to a new surgery to reposition it, the patient remained asymptomatic, with the disappearance of the radicular pain and complete recuperation of prior motor defect.

A patient presented postoperative cerebrospinal fluid (CSF) fistula through the wound, which in our series represents $2.7 \%(\mathrm{n}=1)$. This case was initially treated with lumbar drainage but the external CSF leak reappeared after its withdrawal. Thus it was necessary a new surgery with reparation and sealing.

Infection of the surgical wound was detected on two occasions: $5.5 \%(n=2)$. In the first case, the infectious process only affected the subcutaneous tissue and was resolved after two weeks of specific antibiotic therapy. The second case needed surgical revision checking that the process affected the subcutaneous cellular tissue and superficial muscular fascia. The deep musculature had a normal aspect, for which the system of fixation was not withdrawn. The patient was later submitted to specific antibiotic therapy for two weeks, with a complete resolution of the process.

Analytical study

We found that there was statistically significant rela-

Table 1. Descriptive profiles of patients and pathology

\begin{tabular}{|c|c|c|c|}
\hline & $\begin{array}{r}\text { Isthmic } \\
\text { Spondylolisthesis }{ }^{2}\end{array}$ & $\begin{array}{r}\text { Degenerative } \\
\text { Spondylolisthesis }^{2}\end{array}$ & Total \\
\hline \multicolumn{3}{|l|}{ A) Patient } & \\
\hline \multicolumn{4}{|l|}{ Age (years) } \\
\hline Mean & 44.1 & 64.2 & 57.1 \\
\hline Median & 46 & 68 & 56.5 \\
\hline $\begin{array}{l}\text { Range } \\
\text { Gender (No patients }(\%))\end{array}$ & $30-75$ & $40-82$ & $30-82$ \\
\hline \multicolumn{3}{|l|}{ Gender (No. patients (\%)) } & \\
\hline $\begin{array}{l}\text { Men } \\
\text { Women }\end{array}$ & $9(25 \%)$ & $5(13.9 \%)$ & $14(38.9 \%)$ \\
\hline Sintomatology (No. patients (\%)) & $6(16.6 \%)$ & $16(44.5 \%)$ & $22(61.1 \%)$ \\
\hline None & & & \\
\hline Back Pain & $0(0 \%)$ & $0(0 \%)$ & $0(0 \%)$ \\
\hline Sciatica & $0(0 \%)$ & $0(0 \%)$ & $0(0 \%)$ \\
\hline Neurogenic Claudication & $1(2.7 \%)$ & $5(13.9 \%)$ & $6(16.6 \%)$ \\
\hline Back pain \& Sciatica & $0(0 \%)$ & $0(0 \%)$ & $0(0 \%)$ \\
\hline Back pain \& Sciatica \& N.Claudication & $6(16.6 \%)$ & $8(22.1 \%)$ & $14(38.8 \%)$ \\
\hline \multirow{2}{*}{\multicolumn{3}{|c|}{ Signs(No. patients (\%)) }} & $16(44.4 \%)$ \\
\hline None & & & \\
\hline Motor & $4(11.1 \%)$ & $4(11.1 \%)$ & $8(22.2 \%)$ \\
\hline Sensory & $9(25 \%)$ & $7(19.4)$ & $16(44.4 \%)$ \\
\hline Motor \& Sensory & $1(2.7 \%)$ & $4(11.1 \%)$ & $5(13.8 \%)$ \\
\hline Duration of Symptoms (years) & $2(5.5 \%)$ & $5(13.9 \%)$ & $7(19.4 \%)$ \\
\hline 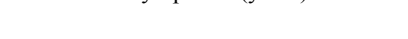 & $5.4 \pm 4.2$ & $6.7 \pm 4.8$ & $6.2 \pm 4.6$ \\
\hline \multicolumn{4}{|l|}{ B) Pathology } \\
\hline \multicolumn{4}{|l|}{ Types (No. patients (\%)) } \\
\hline Isthmic & & & \\
\hline Degenerative & $15(41.0 \%)$ & $21(5830 \%$ & $10(41.0 \%)$ \\
\hline \multicolumn{4}{|l|}{ Surgery Levels (No. patients (\%)) } \\
\hline One & 15 & 19 & $34(94.4 \%)$ \\
\hline Two & $0(0 \%)$ & $2(5.5 \%)$ & $2(5.5 \%)$ \\
\hline Grades ${ }^{8}$ (No. levels (\%)) & \\
\hline I & $4(10.5 \%)$ & $18(47.3 \%)$ & $22(57.8 \%)$ \\
\hline $\begin{array}{ll}11 \\
\mu\end{array}$ & $10(26.3 \%)$ & $4(10.5 \%)$ & $14(36.8 \%)$ \\
\hline III & $1(2.6 \%)$ & $1(2.6 \%)$ & $2(5.2 \%)$ \\
\hline $\mathrm{V}$ & $0(0 \%)$ & $0(0 \%)$ & $0(0 \%)$ \\
\hline Levels (No. levels (\%)) & $0(0 \%)$ & $0(0 \%)$ & $0(0 \%)$ \\
\hline L3-L4 & $0(0,0$ & $3(780 \%)$ & \\
\hline L4-L5 & $5(0 \%)$ & $5(1.8 \%)$ & $3(7.8 \%)$ \\
\hline L5-S1 & $5(13.2 \%)$ & $14(36.8 \%)$ & $19(50 \%)$ \\
\hline Previous discectomy (No. patients (\%)) & $10(26.3 \%)$ & $6(15.7 \%)$ & $16(42.1 \%)$ \\
\hline Yes & $0(0 \%)$ & $5(13.9 \%)$ & $5(13.8 \%)$ \\
\hline No & $15(41.8 \%)$ & $16(44.4 \%)$ & $31(86.2 \%)$ \\
\hline
\end{tabular}


tionship between the sex and the type of spondylolisthesis; isthmic spondylolisthesis is most frequent in men, while degenerative spondylolisthesis is most frequent in women $(\mathrm{p}=0.028)$.

Similarly, we found that the age of the patients was associated with the possibility of the appearance of this lumbar pathology, with Type II being the most frequent after the decade of the 40s, while Type III appears more commonly at a later age, specifically, from the decade of the $50 \mathrm{~s}(\mathrm{p}=0.008)$.

In terms of the most frequently affected lumbar levels, we observed the existence of an association between isthmic spondylolisthesis and the L5-S1 level, and between degenerative spondylolisthesis and

Table 2. Pain scores and improvement at follow-up.

\begin{tabular}{|c|c|c|c|c|}
\hline & $\begin{array}{r}\text { VAS }^{*} \\
\left(\chi^{2} \pm \text { SD }\right)\end{array}$ & $\begin{array}{r}\text { Improvement } \\
(\%)\end{array}$ & Student's T & $\mathbf{p}^{*}$ \\
\hline \multicolumn{5}{|l|}{ Lumbar pain } \\
\hline Preoperatory & $7.7 \pm 0.6$ & -- & -- & -- \\
\hline 3 months postop & $1.3 \pm 0.4$ & 82.8 & 43.8 & $\mathrm{p}<0.01$ \\
\hline 6 months postop & $1.3 \pm 0.4$ & 82.1 & 54.2 & $\mathrm{p}<0.01$ \\
\hline 1 year postop & $1.5 \pm 0.5$ & 79.6 & 62.7 & $\mathrm{p}<0.01$ \\
\hline \multicolumn{5}{|l|}{ Leg pain } \\
\hline Preoperatory & $6.5 \pm 0.6$ & -- & -- & -- \\
\hline 3 months postop & $0.5 \pm 0.5$ & 91.0 & 54.0 & $\mathrm{p}<0.01$ \\
\hline 6 months postop & $0.6 \pm 0.6$ & 90.5 & 47.2 & $\mathrm{p}<0.01$ \\
\hline 1 year postop & $0.9 \pm 0.9$ & 86.3 & 36.0 & $\mathrm{p}<0.01$ \\
\hline
\end{tabular}

*Pain was measured on a 10-point VAS. ** Paired Student's T-test was used to calculate the differences between the preoperatory and postoperatory periods. Significant differences were found $(p<0.01)$

Table 3. Clinical results (Kirkaldy-Willis criteria).

\begin{tabular}{|l|r|}
\hline & No. Patients (\%) \\
\hline Excellent & \\
Good & $29(80.5 \%)$ \\
Fair & $5(14 \%)$ \\
Poor & $2(5.5 \%)$ \\
\hline
\end{tabular}

Table 4. Radiological Results after 1 year of follow up.

\begin{tabular}{|c|c|c|c|}
\hline & $\begin{array}{r}\text { Isthmic Spondylolisthesis } \\
(\text { No. levels (\%)) }\end{array}$ & $\begin{array}{r}\text { Degenerative Spondylolisthesis } \\
\text { (No. levels (\%)) }\end{array}$ & $\begin{array}{r}\text { Total } \\
(\text { No. levels }(\%))\end{array}$ \\
\hline \multicolumn{4}{|c|}{ PLIF (Brantigan et al ${ }^{11}$ ) } \\
\hline Level 5 & $15 / 15(100 \%)$ & $21 / 23(91.3 \%)$ & $36 / 38(94.7 \%)$ \\
\hline Level 4 & $0 / 15(0 \%)$ & $2 / 23(8.7 \%)$ & $2 / 38(5.3 \%)$ \\
\hline Level 3 & $0 / 15(0 \%)$ & $0 / 23(0 \%)$ & $0(0 \%)$ \\
\hline Level 2 & $0 / 15(0 \%)$ & $0 / 23(0 \%)$ & $0(0 \%)$ \\
\hline Level 1 & $0 / 15(0 \%)$ & $0 / 23(0 \%)$ & $0(0 \%)$ \\
\hline \multicolumn{4}{|c|}{ IPLF (Lenke et al ${ }^{12}$ ) } \\
\hline Grade A & $14 / 15(93.3 \%)$ & $20 / 23(87 \%)$ & $34 / 38(89.4 \%)$ \\
\hline Grade B & $1 / 15(6.7 \%)$ & $3 / 23(13 \%)$ & $4 / 38(10.6 \%)$ \\
\hline Grade C & $0 / 15(0 \%)$ & $0 / 23(0 \%)$ & $0(0 \%)$ \\
\hline Grade D & $0 / 15(0 \%)$ & $0 / 23(0 \%)$ & $0(0 \%)$ \\
\hline
\end{tabular}

Downloaded from http://ijssurgery.com/ by guest on April 26, 2023 
L4-L5 lumbar level $(\mathrm{p}=0.024)$.

In order to establish possible clinical prognostic predictive factors, we employed the correlation analysis. We obtained variables such as the age of patients in the moment of intervention, the grade of listhesis, or the duration of the illness since diagnosis until surgery was indicated, were very weakly and indirectly correlated with the VAS improvement after 1 year from the intervention $(\mathrm{r}<-0.2)$. In this way, the older or the longer the illness before surgery, the less was the improvement referred in the pain scales a year after the surgical procedure.

There was no significant difference in the clinical and radiological outcomes between isthmic or degenerative spondylolisthesis $(\mathrm{p}>0.05)$

We did not find variables such as age, sex and the pathology of risk of the patients (arterial hypertension, diabetes mellitus, dyslipemia, hyperuricemia) were associated, neither individually nor in the multivariate analysis, to a greater percentage of postsurgical complications $(\mathrm{p}>0.05)$.

\section{Discussion}

There exist diverse types of spondylolisthesis. Wiltse et al. made the first systematized classification according to the etiology in 1976; later this first classification was modified and completed. ${ }^{13,14}$ As mentioned in this work, we have employed the Wiltse et al. classification ${ }^{2}$ because of its simplicity. We have studied Type II and III spondylolisthesis; type I, IV and $\mathrm{V}$ spondylolisthesis are not the object of this work because the patients are usually complex with other associated lesions and diseases.

In our series we have presented descriptive results similar to those present in the literature both in relation to isthmic and degenerative spondylolisthesis. ${ }^{15-26}$

\section{Treatment}

Generally, it could be said that the treatment is the same in the diverse types of spondylolisthesis. Even though the majority of the patients respond well to conservative treatment, it is estimated that $10-15 \%$ need surgical treatment to resolve the advanced cases with severe symptoms, such as permanent or recurring back pain associated, or not, to neuralgia or neurogenic claudication, decrease in the quality of life, progressive neurological defect or, in some extreme cases, symptoms of cauda equina syndrome with sphincter involvement. ${ }^{27,28}$

The surgery has two aims: to improve the back pain and neurological symptoms, and thus the quality of life, and to detain the progressive vertebral slipping. The absolute indication for surgery comes from the progression of the neurological defect or the cauda equina syndrome.

In the last two decades, the improvement of the surgical techniques has increased the number of patients treated with surgery, with good clinical results. However, there still exists a very important discussion about which is the best surgical technique to treat symptomatic spondylolisthesis; above all in the cases of high degree spondylolisthesis.

The first surgical strategy employed, which complied with the objective of improving the radicular symptoms and neurogenic claudication, was the decompression by means of laminectomy. Lane was the first to use it. ${ }^{29}$ Nevertheless, the inconvenience of this technique was that with time, the instability increased and the progression of the listhesis was accelerated, and thus, the second objective sought with these interventions was not satisfied: it was the detention of progressive slipping. For this reason Vibert et al. stated that laminectomy without fusion should be carried out only on patients with practically rigid segment by reactive sclerosis. ${ }^{30}$

To avoid instability and progression, to correct and improve, if possible, the listhesis, and at least in theory, the back pain, the fusion by means of instrumentation began to be used. This maneuver, at first, was widely debated.

The literature revision, including controlled randomized studies and comparative observational studies, do not allow us to extract definitive evidence on whether the clinical results in short and midterm are better with the instrumented fusion than with the 
non instrumented. However, they allow us to establish, with a reasonable level of evidence, that instrumentation increases the possibilities of obtaining a solid fusion. ${ }^{31,32}$

Nowadays, numerous works can be found where different groups describe different techniques of instrumented fusion..$^{33-40}$

The posterolateral fusion (PLF) diminishes the possibilities of instability, but the proportion of stable fusions is low as it does not allow us to control the biomechanics of the anterior spine..$^{41,42}$ While, the posterior lumbar intersomatic fusion (PLIF) allows us to restore the discal height, facilitate the correction of alignment and balance, immobilize the pathological space, improving in this way the stability, and decompressing the dural sac and the roots. Also, the use of titanium or carbon cages filled with bony graft in this technique diminishes the complications due to the reabsorption of graft and the posterior collapse of the discal space, improving in this way the fusion rates. ${ }^{43}$ Nevertheless, the PLIF is a very aggressive surgical technique, demanding in its carrying out and with a long operating theatre time that facilitates a greater blood loss and increases the possibility of complications. $^{44}$

Even though important publications such as those of Ekman et al..$^{45}$ or revisions of the literature such as by Jacobs et al. ${ }^{46}$ show no significant differences in terms of clinical results in patients with isthmic spondylolisthesis only treated with PLIF or with PLF, the same cannot be stated in terms of the radiological results. Both in our work, and in other studies such as Madan and Boeree, ${ }^{44}$ where they compare the grades of fusion reached by using PLF isolated against PLIF + PLF, there is a tendency towards a better radiological result with the technique used by our group, which could undoubtedly condition the clinical result in the long term.

In the same way in the present study, as well as in the work of Kim et al., ${ }^{47}$ the same conclusion is reached when we talk about degenerative lumbar illness.

The reason for these findings is that while PLF produces a fusion of the transverse apophysis and the lateral region of the facet union, the PLIF creates a fusion of the anterior lumbar column, obtaining a very solid circumferential fusion from the combination of both techniques. ${ }^{47}$ On the other hand, the employment in all our cases of autologous bone obtained from local bony structures, such as laminas or facets, to carry out both the intersomatic and the posterolateral fusion, in place of the iliac crest, meant the elimination of the pain in the donor place, the diminishment of surgical time and a lower blood loss.

There has been a lot debate as to whether reducing the listhesis during the fusion surgery improves or not the results. Agreement exists on that the reduction is the desired objective. From the wide published experience, it can be concluded that when an instrumented reduction wit fusion is performed, less pseudoarthrosis is produced than when only a fusion is carried out. ${ }^{48,49}$

In our patients, using PLIF associated to IPLF with intrasurgical reduction of the listhesis, excellent clinical results have been obtained, with statistically significant improvements a year after intervention $(\mathrm{p}<$ 0.01).

In terms of the radiological results obtained at one year after the intervention, complete fusion in 33 out of 36 patients, we are aware that a follow up of 12 months could be insufficient. Our review of the literature obtained variable results in this sense, finding follow ups that ranged between 3 months and 10 years. ${ }^{50-56}$ With the objective of not producing any lost cases due to a lack of follow up in consultations (that the patient decided not to attend controls after postsurgical clinical improvement), and taking into account, on the one hand, the phases and physiological human bony consolidation times (maximum between 4 and 8 weeks), and on the other hand, our previous experience in the follow up of patients who underwent other types of interventions such as those related with vertebral fractures, we established a maximum follow up of 12 months, leaving open the option of lengthening the follow up depending on the results. The results as regards the clinical and fusion situation at one year of follow up were satisfactory and no patient needed to return to the operating room for pseudarthrosis. For this, the follow up was

Downloaded from http://ijssurgery.com/ by guest on April 26, 2023 
not prolonged.

We believe that the application of the postoperative corset in all the patients systematically for the first 3 post-operative months gave the necessary immobility to the patient and their spine for the attainment of the observed grade of consolidation.

\section{Complications}

In relation to the complications with the technique used in this work, we found in the literature that the associated rate of surgical complications is low, situating our results in the same range as those from other publications. On the contrary, the anterior approaches with intervertebral fusion present a greater risk for the large vessels and other intra and retroperitoneal structures. ${ }^{57}$

The incidence of dural breakage during surgery that is cited in the literature, varies between $5.5 \%$ and $10.1 \%$ (5.8\% -7/120, 5.5\% - $13 / 236,10.1 \%$ - 36/ $356) ., 38,59$ In our series it occurred in only one patient (2.77\%) with degenerative listhesis associated to important alterations of the facet joints and severe stenosis of the canal.

We had a profound infection of the operative area $(2.77 \%)$, similar rate to the other groups that vary between $1.4 \%$ and $3 \%$ of the patients intervened $(2.5 \%$ $-3 / 120,3 \%-73 / 236,1.4 \%-5 / 356,3.5 \%-3 / 86)$.

From a neurological point of view, all our cases evolved favourably in the short and long term. It is interesting to mention that in the immediate postoperative period all the patients referred to improvement or disappearance of radicular pain. This fact could be related with the indirect foraminal decompression produced by the increase of height of the discal space. In the long term, the excellent results obtained in relation to the incorporation of the patients to work, could in part be due to the recommendation which was made to some of the patients in reference to a change in work activity, advice that was made effective in all the cases.

None of our patients presented deep venous thrombosis or the feared pulmonary thromboembolism. In the series presented by Ekman and cols. patients with isthmic spondylolisthesis treated by PLIF, the incidence of each one of these events was of $1.3 \%{ }^{45}$

The possibilities of posterior migration of the intersomatic cages are practically non-existent when the PLIF is associated with fixation with pedicular screws, citing this complication between $0.8 \%{ }^{58}$ and 1.4\%. ${ }^{60}$ Chen and cols. showed in their work that this situation was produced in $7 \%(3 / 42)$ of the cases of posterolateral fixation, with this complication being absent in all of the cases $0 \%$ (46 patients) where posterior fixation is associated. ${ }^{11}$ Periodical radiological controls carried out on our patients showed the correct situation of the intersomatic implants in all the cases, not observing in any occasion posterior slipping of the implanted material.

\section{Prognosis predictive factors}

The correlation analysis let us establish some prognosis factors that were weakly and indirectly associated with better or worse clinical outcome after surgery. The most important were: the age of patients in the moment of intervention, the grade of listhesis and the duration of the illness since diagnosis until surgery was indicated. The last variable had an average of 6.5 years and this is a very long period of time. Similar figures are found in the best published series. In this way, we believe that if the patients do not respond significantly to complete conservative treatment at short term, we think than less than one year, they should be taken into account for early surgical treatment if we want to obtain the best clinical outcomes.

A comparision between the more relevant series in the literature and present study is showed in Table 5.

\section{Conclusions}

According to our experience, spinal surgery by posterior via, associating decompressive laminectomy with intersomatic fusion, posterolateral fusion and fixation with pedicular screws, is the best surgical decision for the patients with spondylolisthesis in those that have failed with the conservative treatment, independent of type or grade of spondylolisthesis. Our results show than, compared with other surgical techniques that are currently still used in this condition, 
this type of surgery allows us to obtain both at short and long term, on the one hand, excellent and significant clinical results, and, on the other hand, greater radiological results than with other procedures. $\mathrm{Nev}$ ertheless, we should always take into account that the prolonged surgical times and the aggressiveness of this type of surgery in comparison with other techniques, could condition the appearance of possible complications and sequelae, for which an adequate surgical training before facing them is compulsory.

The study of clinical prognostic predictive factors is almost nonexistent in the literature and we performed it. Although additional studies are needed in order to develop multifactorial analyses with longer sample sizes, we believe that these statistical results help, among other things, to optimize the time in which these techniques should be indicated to obtain the best outcomes after surgery.

\section{References}

1. Kilian $\mathrm{H}$, Schilderungenneuerbeckenformen und ihresverhaltens in lebened. Mannheim, Verlag Von Bosserman. 1854.

2. Wiltse LL, Newman PH, Macnab I. Classification of spondylolysis and spondylolisthesis. Clin Orthop Relat Res 1976; 117:23-29.

3. Froese Beth B. Lumbar Spondylolysis and Spondylolisthesis. Medscape. http://emedicine.medscape.com/article/ 310235-overview. Accessed 24 March 2009.

4. Vokshoor A, Jamali AR. Spondylolisthesis, Spondylolysis, and Spondylosis. Medscape. http://emedicine.medscape.com/article/ 1266860-overview>de. 2009. Accessed 24 March 2009.

5. Dandy DJ, Shanon MJ Lumbo-sacral subluxation (Group I spondylolisthesis). J Bone Joint Surg Br 1971; 53: 578-595.

6. Ikata T, Miyake R, Katoh S, Morita T, Murase M Pathogenesis of sports-related spondylolisthesis in adolescents. The American Journal of Sports Medicine 1996; 24: 94-98.

7. Cloward RB. Posterior lumbar interbody fusion updated. Clin Orthop Relat Res 1985; 193:16-19.

Table 5. Comparison between the more relevant series in the literature* and present study.

\begin{tabular}{|c|c|c|c|c|c|c|c|c|c|c|c|}
\hline & Study design & $\begin{array}{l}\text { Patients } \\
\text { (No.) }\end{array}$ & $\begin{array}{l}\text { Mean } \\
\text { Age } \\
\text { (Years) }\end{array}$ & $\begin{array}{l}\text { Gender } \\
\text { (Women/ } \\
\text { Men) }\end{array}$ & $\begin{array}{l}\text { Type of Spondy- } \\
\text { lolisthesis }\end{array}$ & $\begin{array}{l}\text { Surgical } \\
\text { Technique }\end{array}$ & $\begin{array}{l}\text { Mean } \\
\text { Follow } \\
\text { up } \\
\text { (Years) }\end{array}$ & $\begin{array}{l}\text { Total Fol- } \\
\text { low up } \\
\text { Rate }(\%)\end{array}$ & $\begin{array}{l}\text { Clinical Satis- } \\
\text { faction } \\
\text { (No.patients } \\
(\%))\end{array}$ & $\begin{array}{l}\text { Fusion Rate } \\
\text { (No.patients } \\
(\%) \text { ) }\end{array}$ & $\begin{array}{l}\text { Major Complica- } \\
\text { tions** } \\
\text { (No.patients (\%)) }\end{array}$ \\
\hline $\begin{array}{l}\text { Ekman et } \\
\text { al. } .^{45}\end{array}$ & Prospective & 86 & 40 & $53 / 33$ & Isthmic & $\begin{array}{l}\text { PLIF } \\
+ \text { PLF }\end{array}$ & 2 & $98 \%$ & $74 / 86(86 \%)$ & --- & $12 / 86(13.9 \%)$ \\
\hline $\begin{array}{l}\text { Periasamy } \\
\text { et al. }{ }^{.2}\end{array}$ & Retrospective & 75 & 48.7 & $30 / 45$ & $\begin{array}{l}\text { Isthmic + Degen- } \\
\text { erative }\end{array}$ & $\begin{array}{l}\text { PLIF } \\
+ \text { PLF }\end{array}$ & 2.4 & --- & $64 / 75(85.3 \%)$ & $\begin{array}{l}71 / 75 \\
(94.6 \%)\end{array}$ & $10 / 75(13.3 \%)$ \\
\hline $\begin{array}{l}\text { Abdu et } \\
\text { al. }{ }^{63}\end{array}$ & Prospective & 63 & 59.7 & $50 / 13$ & Degenerative & $\begin{array}{l}\text { PLIF } \\
+ \text { PLF }\end{array}$ & 4 & $73 \%$ & --- & $\begin{array}{l}47 / 54 \\
(87 \%)\end{array}$ & $9 / 63(14.2 \%)$ \\
\hline Kim et al. ${ }^{47}$ & Prospective & 48 & 53.4 & $35 / 13$ & $\begin{array}{l}\text { Isthmic + Degen- } \\
\text { erative }\end{array}$ & $\begin{array}{l}\text { PLIF } \\
+ \text { PLF }\end{array}$ & 3 & --- & $41 / 48(85.4 \%)$ & $\begin{array}{l}46 / 48 \\
(96 \%)\end{array}$ & $3 / 48(6.2 \%)$ \\
\hline $\begin{array}{l}\text { Suck et } \\
\text { al. }{ }^{43}\end{array}$ & Retrospective & 36 & --- & --- & Isthmic & $\begin{array}{l}\text { PLIF } \\
+ \text { PLF }\end{array}$ & 3.3 & $100 \%$ & $35 / 36(97 \%)$ & $\begin{array}{l}36 / 36 \\
(100 \%)\end{array}$ & $2 / 36(5.5 \%)$ \\
\hline $\begin{array}{l}\text { Cuningham } \\
\text { et al. }{ }^{54}\end{array}$ & Prospective & 31 & 43 & $17 / 14$ & Isthmic & $\begin{array}{l}\text { PLIF } \\
+ \text { PLF }\end{array}$ & 6.33 & $77 \%$ & --- & --- & --- \\
\hline $\begin{array}{l}\text { Madam et } \\
\text { al. }^{44}\end{array}$ & Retrospective & 23 & 41.1 & $9 / 14$ & Isthmic & $\begin{array}{l}\text { PLIF } \\
+ \text { PLF }\end{array}$ & 2.4 & $100 \%$ & $23 / 23(100 \%)$ & $\begin{array}{l}23 / 23 \\
(100 \%)\end{array}$ & $2 / 23(8.6 \%)$ \\
\hline $\begin{array}{l}\text { Wang et } \\
\text { al. }^{50}\end{array}$ & Retrospective & 21 & 52.7 & --- & $\begin{array}{l}\text { Isthmic + Degen- } \\
\text { erative }\end{array}$ & $\begin{array}{l}\text { PLIF } \\
+ \text { PLF }\end{array}$ & 1 & $100 \%$ & $19 / 21(90 \%)$ & --- & $4 / 21(19 \%)$ \\
\hline $\begin{array}{l}\text { La Rosa et } \\
\text { al. }{ }^{56}\end{array}$ & Prospective & 17 & 57.2 & --- & Isthmic & $\begin{array}{l}\text { PLIF } \\
+ \text { PLF }\end{array}$ & 2 & $100 \%$ & $15 / 17(88.2 \%)$ & $\begin{array}{l}17 / 17 \\
(100 \%)\end{array}$ & --- \\
\hline $\begin{array}{l}\text { Present } \\
\text { Study }\end{array}$ & Prospective & 36 & 57.1 & $22 / 14$ & $\begin{array}{l}\text { Isthmic + Degen- } \\
\text { erative }\end{array}$ & $\begin{array}{l}\text { PLIF } \\
+ \text { PLF }\end{array}$ & 1 & $100 \%$ & $34 / 36(94.5 \%)$ & $\begin{array}{l}33 / 36 \\
(91.6 \%)\end{array}$ & $5 / 36(13.8 \%)$ \\
\hline
\end{tabular}

*43-45,47,50,54,56,63 are comparative studies between two or more surgical techniques. Only are shown PLIF + PLF Groups. **Major complications: wound haematoma, wound infection, cerebrospinal fluid fistula, permanent or transient leg pain, deep vein thrombosis, pulmonary embolus.

Downloaded from http://ijssurgery.com/ by guest on April 26, 2023 
8. Meyerding H. Spondylolisthesis: surgical treatment and results. Surg Gynecol Obstet 1932; 54:371-377.

9. Melzack R The Mc Gill. Pain questionnaire: major properties and scoring met-hods. Pain 1975; 1:

277- 299.

10. Kirkaldy-Willis WH, Paine KWE, Cauchoix J, McIvor G. Lumbar spinal stenosis. Clin Orthop Relat Res 1974; 99: 30-52.

11. Brantingan JW, Steffe AD. A carbon fiber implant to aid the interbody lumbar fusion: two - year clinical results in the first 26 patients. Spine 1993; 18:2106-2117.

12. Lenke LG, Bridwell KH, Bullis D, Betz RR, Baldus C, Schoenecker PL. Results of in-situ fusion for ishtmic spondylolisthesis. J Spinal Disord 1992; 5: 433-442.

13. Marchetti PG, Bartolozzi P, Spondylolisthesis: classification of spondylolisthesis as a guideline for treatment. In: The Textbook of Spinal Surgery, 2nd edn. Philadelphia, Lippincott-Raven, 1997:

1211-1254.

14. Hermann MJ, Pizzutillo PD. Spondylolysis and spondylolisthesis in the child and adoslescent. Clin Ortoph Relat Res 2005; 434: 46-54.

15. Greenberg MS, Handbook of Neurosurgery. Thieme, New York. 2006.

16. Robert (zuCoblene). Eineeitenthumlicheangebornelordose, wahrscheinlichbedingtdurcheineverschienbung des korpers des letztenliendenwirbels auf die vordereRache des erstenkreubeinwirbels (spondylolithesiskilian) nebstbemerkungenuber die mechanikdieserbeckenformation, Monatsschr.

Geburtskundeke Frauenkrank 1855;5:81.

17. Neugebauer FL. Einneuerbeitragzurcasuistic and aetiologie der spondylolisthesis. Arch Gynecol 1884; 22: 347.

18. Macnab I. Spondylolisthesis with an intact neural arch: the so-called pseudospondylolisthesis. J Bone Joint Surg Br 1950; 32:325-333.

19. Newman PH. Spondylolisthesis: its cause and effect. Ann R Coll Surg Engl 1955;16:305-323.

20. Iguchi T, Wakami T, Kurihara A, Kasahara K Yoshiya S, Nishida K. Lumbar multilevel degenerative spondylolisthesis: radiological evaluation and factors related to anterolisthesis and retrolisthesis. $J$ Spinal Disord Tech 2002; 15:93-9.
21. Chaput Ch, Padon D, Rush J, Lenehan E, Rahm M. The Significance of Increased Fluid Signal on Magnetic Resonance Imaging in Lumbar Facets in Relationship to Degenerative Spondylolisthesis. Spine 2007; 32:1883-1887.

22. Vogt MT, Rubin D, Valentin RS, Palermo L, Donaldson WF 3rd, Nevitt M, Cauley JA. Lumbar olisthesis and lower back symptoms in elderly white women: the Study of Osteoporotic Fractures. Spine 1998; 23:2640-2647.

23. Kauppila LI, Eustace S, Kiel DP, Felson DT, Wright AM. Degenerative displacement of lumbar vertebrae: a 25-year follow-up study in Framingham. Spine 1998; 23:1868.

24. Cauchoix J, Benoist M, Chassaing V. Degenerative spondylolisthesis. Clin Orthop Relat Res 1976; 115:122-129.

25. Rosenberg NJ. Degenerative spondylolisthesis: predisposing factors. J Bone Joint Surg Am 1975; 57:467-474.

26. Bird HA, Eastmond CJ, Hudson A, Wright V. Is generalized joint laxity a factor in spondylolisthesis? Scand J Rheumatol 1980; 9:203-205.

27. Postacchini F, Cinotti G, Perugia D. Degenerative lumbar spondylolisthesis. II. Surgical treatment. Ital J Orthop Traumatol 1991;17:467-477.

28. Rosenberg NJ. Degenerative spondylolisthesis: Surgical treatment. Clin Orthop Relat Res 1976; 117:112-120.

29. Lane WA. Case of spondylolisthesis with progressive paraplegia after laminectomy. Lancet 1893; 1:991.

30. Vibert BT, SlivaChD, Herkowitz HN. Treatment of instability and spondylolisthesis. Surgical versus nonsurgical treatment. Clin Orthop Relat Res 2006; 443:222-227.

31. Martin CR, Gruszczynski AT, Braunsfurth HA, Fallatah SM, O'Neil J, Wai EK. The surgical management of degenerative lumbar spondylolisthesis. A systematic review. Spine 2007; 32: 1791-1798.

32. Sengupta DK, Herkowitz HN. Degenerative spondylolisthesis. Review of current trends and controversies. Spine 2005; 3(6S): S71-S81.

33. Ryerson EW. Recurrent spondylolisthesis with paralysis: bone splint transplantation. JAMA 1915; 64:24.

34. Hibbs RA, Swift WD Developmental abnormal- 
ities at the lumbosacral juncture causing pain and disability: report of 147 patients treated by the spinal fusion operation. Surg Gynecol Obstet 1929; 48:604. 35. Albee FH. Spondylolisthesis. J Bone Joint Surg 1927; 9: 427.

36. George CM. Spondylolisthesis. Surg Gynecol Obstet 1939; 68:774.

37. Meyerding RD. Spondylolisthesis. J Bone Joint Surg 1931; 13: 39.

38. De Palma AF, Prabhaker M Posterior, posterolateral fusion of the lumbosacral spine. Clin Orthop Relat Res 1966); 47:165.

39. Cloward RB. Spondylolisthesis: treatment by laminectomy and posterior interbody fusion. Review of 100 cases. Clin Orthop Relat Res 1981; 154:74-82. 40. Herkowitz HN, Kun LT. Degenerative lumbar spondylolisthesis with spinal stenosis: A prospective study comparing decompression with decompression and intertransverse process arthrodesis. J Bone Joint Surg 1991; 73A:802-808.

41. Loubresse CG, Bon T, Deburge A, Lassale B, Benoit M. Posterolateral fusion for radicular pain in isthmic spondylolisthesis. Clin Orthop Relat Res 1996; 323:194-201.

42. Vaccaro AR, Ring D, Scuderi G, Cohen DS, Garfin SR. Predictors of outcome in patients with chronic back pain and low-grade spondylolisthesis. Spine 1997; 22:2030-2034.

43. Suk S, Lee C-K, Kim W-J, Lee J-Ho, Cho K-J, $\mathrm{Kim} \mathrm{H}-\mathrm{G}$. Adding posterior lumbar interbody fusion to pedicle screw fixation and posterolateral fusion after decompression in spondylolytic spondylolisthesis. Spine 1997; 22:210-220.

44. Madan S, Boeree NR. Outcome of posterior lumbar interbody fusion versus posterolateral fusion for spondylolytic spondylolisthesis. Spine 2002; 27: 1536-1542.

45. Ekman P, Möller H, Tullberg T, Neumann P, Hedlund R Posterior lumbar interbody fusion versus posterolateral fusion in adult isthmic spondylolisthesis. Spine 2007; 32: 2178-2183.

46. Jacobs WC, Vreeling A, DeKleuver M. Fusion for low-grade adult isthmic spondylolisthesis: a systematic review of the literature. Eur Spine J 2006; 15: 391-402.

47. Kim KT, Lee SH, Lee YH, Bae SC, Suk K-S. Clinical outcomes of 3 fusion methods through the posterior approach in the lumbar spine. Spine 2006; 31:1351-1357; discussion 1358.

48. Burkus JK, Lonstein JE, Winter RB, Denis F. Long-term evaluation of adolescents treated operatively for spondylolisthesis: a comparison of in situ arthrodesis only with in situ arthrodesis and reduction followed by immobilization in a cast. $J$ Bone Joint Surg Am 1992; 74:693-704.

49. Molinari RW, Bridwell KH, Lenke LG, Ungacta FF, Riew KD. Complications in the surgical treatment of pediatric high- grade, isthmic dysplastic spondylolisthesis: a comparison of three surgical approaches. Spine 1999; 24:1701-1711.

50. Wang YP, Fei Q, Qiu GX, et al. Outcome of posterolateral fusión versus circunferencial fusión with cage for lumbar stenosis and low degree lumbar spondylolisthesis. Chin Med Sci J 2006; 21:41-47.

51. La Rosa G, Cacciola F, Conti A, et al. Posterior fusion compared with posterior lumbar interbody fusion in segmental spinal fixation for adult spondylolisthesis. Neurosurg focus 2001; 10: E9.

52. Inamdar DN, Alagappan M, Shyan L, et al. Posterior lumbar interbody fusión versus intertransverse fusion in the treatment of lumbar spondylolisthesis. J Orthop Surg HK 2006; 14:21-26.

53. Farrokhi MR, Rahmanian A, Masoudi MS. Posterolateral versus posterior interbody fusión in isthmic spodylolisthesis. J Neurotraum 2012; 29: 1567-1573.

54. Cunningham JE, Elling EM, Milton AH, et al. What is the optimum fusion technique for adult spodylolisthesis PLIF or PLF? A long- term prospective cohort comparison study. J Spinal Disord Tech 2013; 26: 260-267.

55. Dehoux E, Fourati E, Madi K et al. Posterolateral versus interbody fusión in istmic spondylolisthesis: functional results in 52 cases with a minimum follow up of 6.5 years. Acta Orthop Belg 2004; 70: 578-582. 56. La Rosa G, Conti A, Cacciola F, et al. Pedicle screw fixation for isthmic spondylolisthesis: does posterior lumbar interbody fusion improve outcome over posterolateral? J Neurosurg 2003; 99: 90-94. 57. Kulkarni SS, Lowery GL, Ross RE, Ravi Sankar $\mathrm{K}$, Lykomitros V. Arterial complications following anterior lumbar interbody fusion: report of eight cases. Eur Spine J 2003; 12: 48-54.

58. McAfee PC, DeVine JG, Chaput ChD, Prybis 
BG, Fedder IL, Cunningham BW, Farrell DJ, Hess SJ, Vigna FE. The indications for interbody fusion cages in the treatment of spondylolisthesis. Analysis of 120 cases. Spine 2005; 30 (6S): S60-S65.

59. Ray CD. Threaded titanium cages for lumbar interbody fusions. Spine 1997; 22:667-679. (49). 60. Kuslich SD, Ulstrom CL, Griffith SL, Ahern JW, Dowdle JD. The BagbyKuslich method of lumbar interbody fusion: history, techniques, and 2-year follow up results of a United States prospective, multicenter trial. Spine 1998; 23:1267-1278.

61. Chen L, Yang H, Tang T. Cage migration in spondylolisthesis treated with posterior lumbar interbody fusion using BAK cages. Spine 2005;

30:2171-2175.

62. Periasamy K,Shah K, Wheelwright E. Posterior lumbar interbody fusion using cages with instrumented posterolateral fusion: a study of 75 cases. $A c-$ ta Orthop Belg 2008; 74: 240-248.

63. Abdu WA, Lurie JD, Spratt KF et al. Degenerative spondylolisthesis: does fusion method influence outcome? Four-year results of the spine patient outcomes research trial. Spine (Phila Pa 1976) 2009; 34:
2351-2360.

\section{Acknowledgements}

We thank Javier Hernandez Vicente, MD, who just retired, for his ideas and excellent labour as a neurosurgeon.

\section{Disclosures}

The authors report no relevant financial disclosures.

\section{Corresponding Author}

Monica Lara, Department of Neurosurgery, Son Espases University Hospital, Carretera de Valldemossa, 79 07010, Mallorca, Spain.mnclr23@gmail.com

Published 9 June 2015.

This manuscript is generously published free of charge by ISASS, the International Society for the Advancement of Spine Surgery. Copyright @ 2015 ISASS. To see more or order reprints or permissions, see http://ijssurgery.com. 